\title{
Evaluation of Home Medical Care Pharmacists' Services by Physicians, Nurses, Care Managers, and Home Helpers: A Mail Survey
}

\author{
Atsuhiko Sano \\ Showa University \\ Mao Ishida \\ Showa University \\ Masato Nakazawa \\ Showa University \\ Naomi Kurata \\ Showa University \\ Keiko Kishimoto \\ Showa University
}

Tanabe Pharmacy Inc. Co.

Keita Shibata ( $\nabla$ kshibata@pharm.showa-u.ac.jp )

\section{Keywords:}

Posted Date: December 30th, 2020

DOl: https://doi.org/10.21203/rs.3.rs-135910/v1

License: (a) (i) This work is licensed under a Creative Commons Attribution 4.0 International License. Read Full License 


\section{Abstract}

The authors have requested that this preprint be removed from Research Square. 